\title{
Indicadores nacionais sobre TIC e cultura: perspectiva qualitativa $^{1}$
}

\author{
Juliana Doretto \\ Jornalista, doutora em Ciências da \\ Comunicação pela Universidade \\ Nova de Lisboa e mestre na mesma \\ área pela Universidade de São Paulo \\ (USP). É analista de informação do \\ Centro Regional de Estudos para o \\ Desenvolvimento da Sociedade da \\ Informação (Cetic). \\ E-mail: jdoretto@gmail.com
}

Resumo: A pesquisa TIC Cultura, desenvolvida pelo CGI.br por meio do Cetic.br, tem como objetivo produzir indicadores e análises que possibilitem compreender como o acesso às tecnologias de informação e comunicação e os usos que se fazem delas modificam práticas culturais da população brasileira, e como as TIC estão sendo incorporadas pelos equipamentos culturais em sua rotina interna de funcionamento e também na relação com o público. Neste artigo, analisamos um recorte dos dados levantados na fase qualitativa do projeto, com enfoque nos jovens de 15 a 17 anos.

Palavras-chave: Cultura; Tecnologias; Consumo cultural; Grupo focal.

\section{National indicators on ICT and culture: qualitative perspective}

Abstract: The research TIC Cultura [ICT in Culture], developed by CGI.br through Cetic.br, aims to produce indicators and analysis that allow to understand how the access to information and communication technologies and their utilization can change cultural practices of Brazilian population. The survey investigates also how ICT are being incorporated by cultural spaces in internal administration routine and in the relationship with the people. In this study, we analyze some data that came from the qualitative phase of the project, focusing on 15-17-yearold adolescents.

Keywords: Culture; Technologies; Cultural consumption; Focus group.

\footnotetext{
${ }^{1}$ Artigo originalmente apresentado ao GP Mídia, Culturas e Tecnologias Digitais na América Latina do XVI Encontro dos Grupos de Pesquisa em Comunicação, evento componente do XXXIX Congresso Brasileiro de Ciências da Comunicação, realizado de 5 a 9 de setembro de 2016.
} 


\section{Introdução}

Este artigo tem como objetivo apresentar resultados preliminares da pesquisa desenvolvida pelo CGI.br por meio do Cetic.br "TIC Cultura" cujo objetivo é investigar a influência das tecnologias de informação e comunicação nas práticas culturais da população brasileira. Será apresentada neste texto a análise preliminar de um recorte dos dados coletados: grupos focais com jovens de 15 e 17 anos, de diferentes classes sociais, em São Paulo (SP), Vitória de Santo Antão (PE) e Cachoeira do Sul (RS).

"'Cultura' é considerada uma das duas ou três palavras mais complexas de nossa língua", escreve Terry Eagleton (2005: 9). "As definições da cultura são numerosas", afirma Santaella (2003: 30), "tanto o problema quanto o interesse da sociologia da cultura podem ser percebidos de imediato na dificuldade do termo que obviamente a define: 'cultura'", atesta Williams (2000: 10). Os trechos, retirados de partes introdutórias de obras que se voltaram ao estudo da cultura, denotam a complexidade do conceito, que tem diferentes acepções, em diferentes campos e modo de estudo. Usamos aqui a descrição breve de Williams, que condensa o processo analítico que tem atravessado os estudos da cultura.

Assim, há certa convergência prática entre (i) os sentidos antropológico e sociológico de cultura "como modo de vida global" distinto, dentro do qual percebe-se, hoje, um "sistema de significações" bem definido não só como essencial, mas como essencialmente envolvido em todas as formas de atividade social, e (ii) o sentido mais especializado, ainda que também mais comum, de cultura como "atividades artísticas e intelectuais", embora estas, devido à ênfase em um sistema de significações geral, sejam agora definidas de maneira muito mais ampla, de modo a incluir não apenas as artes e as formas de produção intelectual tradicionais, mas também todas as "práticas significativas" - desde a linguagem, passando pelas artes e filosofia, até o jornalismo, moda e publicidade - que agora constituem esse campo complexo e necessariamente extenso. (Ibid.: 13, grifos do autor).

É para esse segundo sentido de cultura que olhamos neste artigo, ainda que dentro da visão mais restrita, que a entende como "setor cultural". E, aqui, utilizamos a conceituação de Sunkel (2015: 172, tradução nossa), que o enxerga abarcando "desde atividades artísticas - como as artes cênicas ou visuais incluindo o patrimônio material e imaterial, até as indústrias culturais e criativas (cinematográfica, editorial e musical, entre outras)". No entanto, o autor chileno não deixa de incluir as Tecnologias de Informação e Comunicação (TIC) no setor cultural, "na medida em que elas tiveram um impacto profundo sobre as formas de produção, circulação e consumo de bens culturais". Nesse sentido, Santaella diz que, enquanto o advento da indústria cultural embaçou as barreiras entre as culturas "eruditas" (ou das elites) e popular, as novas tecnologias inauguram o que foi chamado por ela de "cultura das mídias". Nos anos 1980, antes da disseminação da informática e da rede mundial de computadores, a autora brasileira já notava que tecnologias como o videocassete, o videogame e o controle remoto modificavam a produção e o consumo cultural, inaugurando processos distintos da lógica que regia a indústria cultural:

Contrariamente a esta que é essencialmente produzida por poucos e consumida por uma massa que não tem poder de interferir nos produtos simbólicos que consome, a cultura das mídias [...] começava a possibilitar aos seus consumidores a escolha entre produtos simbólicos alternativos. (SANTAELLA, 2003: 52-53).

Segundo a pesquisadora, "mídia" acabou se tornando, ao longo dos anos, termo genérico para designar qualquer processo de comunicação mediado por computador.

Essa nova lógica, ao mesmo tempo que possibilita o nascimento de produtos, mercados e hábitos culturais e aumenta a interação entre culturas, torna-se um 
desafio para a preservação da diversidade, já que, apesar das possibilidades múltiplas de produção e distribuição de bens culturais, o consumo se concentra em poucas plataformas, que não apenas surgem observando lógicas mercantis como também são apropriadas por outras indústrias culturais como forma de disseminação e circulação de seus conteúdos. Grandes e populares empresas, como Google (e YouTube), Facebook, Apple, Amazon e Yahoo, são os principais intermediários entre a população e os produtores culturais, sejam eles complexos industriais organizados ou profissionais independentes, e essa mediação se baseia frequentemente num círculo vicioso de audiência (e, consequentemente, em investimento em estratégias de divulgação): quanto mais "cliques", maior a visibilidade do produto cultural. Cádima (2013: 28) diz que o posicionamento desses grandes conglomerados "aproxima-se, no fundo, da caracterização algo caricatural feita por Eli Pariser sobre os novos gatekeepers, ou guardiões da informação, não já os jornalistas, mas, doravante, cada vez mais os próprios algoritmos que estão na base informacional destas plataformas".

No campo da cultura, a preservação da diversidade tem sido uma das pautas promovidas pela Organização das Nações Unidas para a Educação, a Ciência e a Cultura (Unesco) e que culminou com o estabelecimento da Convenção sobre a Proteção e Promoção da Diversidade das Expressões Culturais, de 2005, ratificada por 140 países - pelo Brasil, em 2007. O texto do documento diz que "constatando que os processos de globalização, facilitado pela rápida evolução das tecnologias de comunicação e informação [...] constituem também um desafio para a diversidade cultural, especialmente no que diz respeito aos riscos de desequilíbrios entre países ricos e pobres", numa clara preocupação com as diferenças de poder econômico e mercantil entre o Norte e o Sul globais. Vieira (2009), em tese de doutorado que analisa o papel normativo da Unesco por meio da Convenção, aponta que a formulação do texto foi, para além de uma iniciativa da agência, o resultado de reivindicações sociais que emergiam enquanto se fortaleciam os novos rearranjos da economia global:

O instrumento foi resultado de uma dinâmica social mais ampla no interior da qual diferentes interesses e valores - a luta pela definição da natureza dos bens simbólicos - foram disputados por distintos atores sociais, revelando assim as lutas travadas no decorrer do processo, e, consequentemente, os desequilíbrios na balança de poder daí decorrentes. Nesse sentido, o papel da Unesco nesse processo, se analisado pela lente da sociologia configuracional eliasiana, não pode ser entendido a não ser como uma síntese de um processo mais amplo que condensa as lutas travadas em torno da defesa da diversidade cultural como um bem universal, disputas essas que também contribuíram para elevar a organização onusiana à condição de fórum de legitimação de sentido no ambiente da globalidade. (Ibid.: 267).

No Brasil, o Plano Nacional de Cultura, elaborado pelo Ministério da Cultura (MinC) em 2010, reverbera as preocupações expostas na convenção da Unesco. O conjunto de diretrizes para a formulação de políticas públicas estabelece 53 metas, a serem cumpridas até 2020, que "garantam a valorização, o reconhecimento, a promoção e a preservação da diversidade cultural existente no Brasil" (BRASIL, 2010c, grifos nossos), segundo descrição do programa no site do ministério. Na lei $\mathrm{n}$ o 12.343, que estabelece o plano, o art. 3ㅇ, § IV, diz que compete ao Poder Público

proteger e promover a diversidade cultural, a criação artística e suas manifestações e as expressões culturais, individuais ou coletivas, de todos os grupos étnicos e suas derivações sociais, reconhecendo a abrangência da noção de cultura em todo o território nacional. (Id., 2010b: 3).

Para auxiliar o monitoramento das metas propostas pelo Plano Nacional de Cultura, o MinC tem desenvolvido o Sistema Nacional de Informações 
e Indicadores Culturais (SNIIC), que pretende reunir informações culturais atualizadas num banco de dados centralizado e aberto para consulta de toda a população. Nesse sentido, a Unesco também advoga que o levantamento de indicadores sistemáticos e comparados internacionalmente é necessário para medir o impacto de políticas e iniciativas culturais e, para isso, propõe uma metodologia de medição, divulgada pela publicação "Unesco Framework for Cultural Statistics":

Um quadro estatístico cultural internacional gostaria de maximizar a comparabilidade internacional sempre que pertinente e viável fazê-lo. A nível nacional, existem também as exigências de dados para estabelecer políticas baseadas em evidências para informar os países sobre o seu estatuto em comparação com outras nações da região ou do mundo. (UNESCO-UIS, 2009: 11).

\section{Pesquisa TIC Cultura}

No Brasil, os indicadores culturais quantitativos de caráter nacional têm se dedicado à medição de números de equipamentos culturais, como o "Sistema de informações e indicadores culturais", do IBGE (BRASIL, 2013), e o "Cultura em números" (2010a), realizado pelo MinC, ou às práticas culturais que se realizam

${ }^{1}$ Como a pesquisa "Públicos de cultura", realizada pelo Sesc (SERVIÇO SOCIAL DO COMÉRCIO, 2013). fora do ambiente on-line ${ }^{1}$.

No campo da relação entre cultura e tecnologias, a investigação coordenada por Nilda Jacks, da Universidade Federal do Rio Grande do Sul, por meio da formação da rede acadêmica Brasil Conectado, envolveu pesquisadores nos 26 estados brasileiros e no Distrito Federal e buscou mapear o consumo midiático de jovens brasileiros, com foco nas plataformas digitais e nos processos de convergência midiática, e também o comportamento desses jovens na rede social Facebook. Ainda que o olhar não esteja especificamente nas práticas culturais, o projeto traz dados que dialogam com nosso objeto, levando em conta a imbricação entre acesso à cultura e sua produção por meio da tecnologia e as mídias, como demonstra Santaella (2003) e já referido aqui. Numa publicação dos dados preliminares da investigação (o relatório final ainda não está disponível), com recorte sobre 50 jovens de classe $\mathrm{C}$, moradores de capitais dos estados mais populosos de cada região brasileira, a equipe ressalta as diferenças na infraestrutura de rede pelo país (já que nem todos os estados possuem oferta de banda larga) e de poder econômico ("a mesma renda de jovens em diferentes estados não implica posições sociais semelhantes"). Além disso, diz que:

os dados do estudo piloto evidenciam a relação entre posse das tecnologias e as transformações no consumo dos meios tradicionais, o uso dos meios para promover e cultivar relacionamentos, a predominância de práticas de consumo simultâneo de meios de comunicação e a importância da música na compreensão do consumo juvenil, que é atravessado pelas possibilidades estruturais de acesso, configurando as práticas dos jovens investigados (SCHMITZ et al., 2014).

Nesse cenário de transformações tecnológicas e preocupações com as desigualdades no acesso a bens culturais e formas e ferramentas para sua produção, e entendendo que o panorama de investigação em âmbito nacional sobre TIC e práticas culturais ainda é carente de estudos, o Centro Regional para o Desenvolvimento da Sociedade da Informação sob os auspícios da Unesco (Cetic. br), departamento do Núcleo de Informação e Coordenação do Ponto BR (NIC.br) e ligado ao CGI.br (Comitê Gestor da Internet no Brasil), deu início à pesquisa TIC Cultura. O Cetic.br é responsável pela produção de indicadores e estatísticas sobre a disponibilidade das TIC no Brasil, considerando que o provimento desses dados é fundamental para a elaboração e monitoramento de políticas públicas relacionadas à tecnologia e também para a investigação acadêmica. Para o planejamento das pesquisas elaboradas pelo centro e posterior avaliação de resultados, grupos de 
especialistas de diversos setores da sociedade (governo, organismos internacionais, academia e sociedade civil) são formados e se reúnem periodicamente.

Assim,

a pesquisa TIC Cultura tem como objetivo investigar o consumo de bens culturais e sua relação com as TIC, compreendendo como o acesso às tecnologias de informação e comunicação e os usos que se fazem delas modificam práticas culturais da população brasileira. (CETIC.BR, [s.d.]).

Para tanto, uma etapa qualitativa, com grupos focais, foi realizada em março de 2016 para investigar as práticas culturais e consumo de cultura na Internet. Os objetivos específicos dessa fase são:

1) investigar os hábitos dos indivíduos em relação ao consumo de cultura na Internet;

2) investigar processos de criação de bens culturais pelos indivíduos na Internet.

A escolha dos grupos (e não de entrevistas individuais) deveu-se ao fato de que "oferece dinâmicas e formas - não disponíveis em entrevistas individuais - de induzir, estimular, e elaborar interpretações da audiência" (HANSEN et al., 1998: 262, tradução nossa). Ou seja, interessava-nos aqui menos os comportamentos pessoais e mais a compreensão social sobre o acesso às TIC e seus usos para práticas culturais, buscando detectar processos mais amplos, que atravessam as experiências específicas.

Adicionalmente, o projeto visa a realizar um módulo quantitativo com a população de 10 anos ou mais, a ser incluído na coleta de dados da pesquisa TIC Domicílios, realizada anualmente pelo Cetic.br, que mapeia o acesso à infraestrutura de TIC nos domicílios urbanos e rurais do país e as formas de uso dessas tecnologias. A coleta desses dados está prevista para ocorrer a partir de 2017, e a análise da fase qualitativa do projeto guiará a produção do questionário a ser aplicado com a população.

Por fim, a pesquisa está fazendo um levantamento quantitativo de uma amostra representativa de equipamentos culturais formais (registrados em um cadastro oficial), públicos e privados. Esses cadastros envolvem listagens fornecidas por órgãos ligados ao Ministério da Cultura: bibliotecas (cadastradas pelo Sistema Nacional de Bibliotecas), museus (pelo Instituto Brasileiro de Museus), teatros (pela Fundação Nacional de Artes), salas de cinema (pela Agência Nacional de Cinema), patrimônio material (listados pelo Instituto do Patrimônio Histórico e Artístico Nacional); Pontos de Cultura (definidos pelo próprio MinC); e arquivos (em cadastro aberto pelo Conselho Nacional de Arquivos). Até março de 2017 serão realizadas entrevistas, por telefone, com os gestores de cada entidade. Entre os objetivos específicos dessa etapa estão:

1) mapear a infraestrutura TIC disponível nos equipamentos culturais públicos e privados brasileiros;

2) investigar as atividades realizadas com o uso de TIC, com foco na gestão dos equipamentos, no contato com os públicos, na digitalização dos acervos materiais e na formação de acervos digitais;

3) compreender as motivações e barreiras para a adoção das TIC nesses equipamentos culturais.

Neste artigo, apresentaremos a análise de um pequeno recorte na fase qualitativa da pesquisa, com alguns resultados preliminares. A seguir, falaremos em detalhe como a investigação foi desenhada. 
${ }^{2}$ A classificação é baseada no Critério de Classificação Econômica Brasil, conforme definido pela Associação Brasileira de Empresas de Pesquisa (Abep). A entidade utiliza a posse de alguns itens duráveis de consumo doméstico e o grau de instrução do chefe da família declarado. A posse dos itens estabelece um sistema de pontuação em que a soma para cada domicílio resulta na classificação como classes econômicas A1, A2, B1, B2, C, $D$ e $E$. Para a análise dos dados, essas categorias foram sintetizadas em $A B, C$ e DE.

${ }^{3}$ Os municípios localizados a cerca de 100 km de distância da capital de seus respectivos Estados e com população de mais de 100 mil habitantes foram classificados como "interior próximo". Já os municípios localizados a mais de $100 \mathrm{~km}$ da capital e com população de até 100 mil habitantes foram considerados como "interior distante".

${ }^{4}$ As crianças não foram investigadas pela especificidade metodológica necessária para esse trabalho.

5 "Manual for Measuring ICT Access and Use by Households and Individuals" (ITU, 2014).

\section{Abordagem qualitativa: grupos focais}

Foram realizados 24 grupos focais, buscando formar a mais diversificada amostra possível. Foram levadas em consideração variáveis que podem influenciar fortemente os hábitos culturais na Internet, por conta de poder de compra, acesso a tecnologias, habilidades para o uso delas e boa conexão de rede etc. São elas:

1) classe social (de A a E, segundo classificação da Associação Brasileira de Empresas de Pesquisa ${ }^{2}$ );

2) escolaridade (até Ensino Médio completo e superior completo);

3) região geográfica (capitais, interior próximo e interior distante das cinco regiões brasileiras ${ }^{3}$, envolvendo 12 cidades). A referência é utilizada para garantir a identificação de eventuais diferenças entre a população das áreas mais distantes dos centros urbanos e a das capitais, onde, em geral, mais opções de equipamentos culturais estão disponíveis.

4) faixa etária, que variou entre 15 e 60 anos (os entrevistados foram divididos em quatro grupos, de acordo com a idade: de 15 a 17 anos; de 22 a 26 anos, de 30 a 40 anos; e de 45 a 60 anos). ${ }^{4}$

Cada grupo focal envolveu de sete a nove participantes, que foram previamente recrutados por telefone (procura aleatória) e convidados a comparecer em data determinada à sala de discussão. Era requisito prévio ser usuário de Internet, o que para as pesquisas do Cetic.br significa dizer que usaram a rede nos últimos três meses, seguindo classificação da União Internacional de Telecomunicações (International Telecommunication Union, em inglês) ${ }^{5}$. Esse recrutamento e o trabalho de campo pelo país foram realizados por profissionais do lbope Inteligência. O quadro 1 sintetiza essa organização.

O questionário aplicado aos grupos foi estruturado a partir de quatro dimensões, que, entendemos, perpassam as práticas culturais midiáticas, de acordo com o exposto em nosso marco conceitual. Em cada uma delas, foram formuladas perguntas secundárias de pesquisa:

1) Dimensão de acesso: Qual o papel exercido pela Internet no acesso a bens e conteúdos culturais? Sob quais condições a Internet se apresenta como local de consumo de cultura? E como a rede possibilita o acesso à informação sobre bens e conteúdos culturais de forma ampla a todos e todas?

2) Dimensão de diversidade: Como a Internet influencia na diversidade dos conteúdos consumidos, tendo em vista a importância da difusão de bens e serviços de cultura de origem nacional, regional e independente? Como as aplicações e plataformas utilizadas interferem na escolha dos conteúdos a serem consumidos? Quais as estratégias utilizadas para acessar conteúdos on-line e/ou off-line?

3) Dimensão econômica: Quais as estratégias utilizadas pelos indivíduos ao optarem por adquirir ou não conteúdos culturais na Internet? Quais as percepções sobre os conteúdos pagos e gratuitos on-line? Qual a percepção sobre a assinatura de plataformas de conteúdo sob demanda?

4) Dimensão criativa/simbólica: De que forma os indivíduos percebem a Internet como espaço para a criação de conteúdos culturais e compartilhamento de informações relacionadas ao universo da cultura? Em que plataformas compartilham sua produção? 


\begin{tabular}{|c|c|c|c|c|c|c|c|}
\hline Região & Localização & UF & Município & Idade & Escolaridade & Classe & $\begin{array}{c}\text { Quantidade } \\
\text { de grupos }\end{array}$ \\
\hline \multirow{4}{*}{ Norte } & \multirow[t]{2}{*}{ Capital } & \multirow[t]{2}{*}{ AM } & \multirow[t]{2}{*}{ Manaus } & 16 a 17 anos & $\begin{array}{l}\text { Até Ensino Médio } \\
\text { completo }\end{array}$ & C & 1 \\
\hline & & & & 30 a 40 anos & Superior & $A / B$ & 1 \\
\hline & \multirow[b]{2}{*}{ Interior próximo } & \multirow[b]{2}{*}{ AM } & \multirow{2}{*}{$\begin{array}{l}\text { Presidente } \\
\text { Figueiredo }\end{array}$} & 45 a 60 anos & Superior & C & 1 \\
\hline & & & & 22 a 26 anos & $\begin{array}{l}\text { Até Ensino Médio } \\
\text { completo }\end{array}$ & $D / E$ & 1 \\
\hline \multirow{6}{*}{ Nordeste } & \multirow[b]{2}{*}{ Capital } & \multirow[b]{2}{*}{$\mathrm{PE}$} & \multirow[b]{2}{*}{ Recife } & 22 a 26 anos & Superior & C & 1 \\
\hline & & & & 45 a 60 anos & $\begin{array}{l}\text { Até Ensino Médio } \\
\text { completo }\end{array}$ & $D / E$ & 1 \\
\hline & \multirow[t]{2}{*}{ Interior próximo } & \multirow[t]{2}{*}{$\mathrm{PE}$} & \multirow{2}{*}{$\begin{array}{l}\text { Vitória de Santo } \\
\text { Antão }\end{array}$} & 16 a 17 anos & $\begin{array}{l}\text { Até Ensino Médio } \\
\text { completo }\end{array}$ & $A / B$ & 1 \\
\hline & & & & 30 a 40 anos & Superior & C & 1 \\
\hline & \multirow{2}{*}{ Interior distante } & \multirow{2}{*}{ PE } & \multirow{2}{*}{ Arcoverde } & 22 a 26 anos & $\begin{array}{l}\text { Até Ensino Médio } \\
\text { completo }\end{array}$ & $D / E$ & 1 \\
\hline & & & & 45 a 60 anos & Superior & $A / B$ & 1 \\
\hline \multirow{6}{*}{ Centro-Oeste } & \multirow[b]{2}{*}{ Capital } & \multirow[b]{2}{*}{ GO } & \multirow[b]{2}{*}{ Goiânia } & 22 a 26 anos & Superior & C & 1 \\
\hline & & & & 16 a 17 anos & $\begin{array}{l}\text { Até Ensino Médio } \\
\text { completo }\end{array}$ & $A / B$ & 1 \\
\hline & \multirow{2}{*}{ Interior próximo } & \multirow[t]{2}{*}{ GO } & \multirow[t]{2}{*}{ Anápolis } & 30 a 40 anos & $\begin{array}{l}\text { Até Ensino Médio } \\
\text { completo }\end{array}$ & $D / E$ & 1 \\
\hline & & & & 45 a 60 anos & Superior & $A / B$ & 1 \\
\hline & \multirow{2}{*}{ Interior distante } & \multirow{2}{*}{ GO } & \multirow{2}{*}{ Jaraguá } & 22 a 26 anos & $\begin{array}{l}\text { Até Ensino Médio } \\
\text { completo }\end{array}$ & C & 1 \\
\hline & & & & 45 a 60 anos & $\begin{array}{l}\text { Até Ensino Médio } \\
\text { completo }\end{array}$ & $D / E$ & 1 \\
\hline \multirow{4}{*}{ Sudeste } & \multirow[t]{2}{*}{ Capital } & \multirow[t]{2}{*}{ SP } & \multirow[t]{2}{*}{ São Paulo } & 15 a 17 anos & $\begin{array}{l}\text { Até Ensino Médio } \\
\text { completo }\end{array}$ & $D / E$ & 1 \\
\hline & & & & 30 a 40 anos & Superior & $A / B$ & 1 \\
\hline & \multirow[t]{2}{*}{ Interior distante } & SP & Avaré & 22 a 26 anos & $\begin{array}{l}\text { Até Ensino Médio } \\
\text { completo }\end{array}$ & C & 1 \\
\hline & & & & 30 a 40 anos & Superior & $A / B$ & 1 \\
\hline & & & & 22 a 26 anos & Superior & $A / B$ & 1 \\
\hline & Capital & RS & Porto Alegre & 45 a 60 anos & $\begin{array}{l}\text { Até Ensino Médio } \\
\text { completo }\end{array}$ & C & 1 \\
\hline Sul & Intorior dictonto & $D C$ & Cachoeira & 16 a 17 anos & $\begin{array}{l}\text { Até Ensino Médio } \\
\text { completo }\end{array}$ & C & 1 \\
\hline & & & do Sul & 30 a 40 anos & $\begin{array}{c}\text { Até Ensino Médio } \\
\text { completo }\end{array}$ & $D / E$ & 1 \\
\hline Totais & & & & & & & $\begin{array}{c}24 \\
\text { grupos }\end{array}$ \\
\hline
\end{tabular}


${ }^{6}$ Nesse primeiro recorte, não analisaremos a categoria gênero.

\section{Discussões}

Neste artigo, analisaremos preliminarmente três dos 24 grupos focais. Elegemos o recorte de faixa etária (jovens de 15 a 17 anos), com representantes de todas as classes sociais e moradores das três divisões geográficas da pesquisa ${ }^{6}$ : capital, interior próximo e interior distante. Assim, foram analisadas, respectivamente, as discussões de São Paulo (SP), Vitória de Santo Antão (PE) e Cachoeira do Sul (RS).

Os jovens moradores da cidade pernambucana destacam a ida constante à capital, Recife, para ter acesso a equipamentos e ações culturais (off-line). No caso de Cachoeira do Sul (RS), os deslocamentos ocorrem até cidades de maior porte, próximas ao município. É importante observar que eram jovens de classe C: ou seja, há restrições financeiras para viajar. Já em São Paulo, como os jovens pertenciam às classes $D$ e $E$, percebe-se que a ampla oferta cultural da capital fica sublimada por conta de dificuldades para custear transporte e, por vezes, ingressos a eventos e instituições. Todos os entrevistados tinham algum acesso à Internet e possuíam um dispositivo que permitia a conexão, como computador e celular (o mais referido). Os tablets não apareceram com destaque, em nenhuma das discussões, como dispositivo utilizado. E a Internet disponível apenas no telefone celular foi ressaltada no grupo do município gaúcho, ainda que os jovens pertencessem a uma classe mais alta do que os de São Paulo - o que confirma o que foi proposto nos resultados preliminares da pesquisa coordenada por Jacks (SCHMITZ, D. et al., 2014), apresentado anteriormente.

Nesse cenário, nota-se, em termos de acesso e de decisões econômicas, a permanência das mídias tradicionais nos hábitos narrados por todos os jovens. O rádio, por exemplo, migra para o celular, sobretudo em deslocamentos em transporte público (por meio de aplicativos ou rádio convencional), mas pode persistir como aparelho comum na escuta em casa:

Moderadora: No rádio, quando vocês falam rádio, é pelo celular ou é rádio aparelho?

Rádio aparelho.

Moderadora: Ninguém escuta pelo celular?

Também.

É difícil.

Moderadora: Por quê?

Porque no rádio é mais alto, no telefone é baixo.

Você vai escutar no ônibus. (Cachoeira do Sul)

Tem pessoal que acessa rádio para ouvir comentário, jornal, eu costumava colocar na 97.7 para ouvir comentários de futebol, alguma coisa assim [...].

É verdade. Também gosto bastante. (São Paulo)

A TV a cabo, e isso inclui os canais usuais, para além do Netflix (serviço de vídeo on demand), também continua a ser consumida, ainda que os de menor poder aquisitivo recorram à casa de parentes que paguem pelo serviço para poder vêla. Os canais a cabo são considerados variados e de melhor qualidade que a TV aberta, com a ressalva de que (e isso inclui o Netflix) os episódios mais recentes das séries só possam ser vistos na Internet, por meio de streaming. Isso mostra que o vídeo on demand não vem substituindo outras formas de consumo de audiovisual, mas se torna uma nova opção, assim como serviços para assistir a vídeos on-line.

Por outro lado, o celular substitui os tocadores de MP3, e o consumo de música é em geral off-line: fazem-se downloads de músicas para a escuta no dispositivo ou ainda, nas classes de rendimento mais baixo, a troca de arquivos entre telefones também é prática comum, o que denota que os jovens costumam limitar a 
navegação on-line no celular a situações em que a rede é imprescindível (isso pode ser um aspecto que acentua o consumo limitado a poucas plataformas, discussão que está associada à prática de zero rating estabelecida por algumas empresas, em que o acesso a determinadas páginas não é descontado do pacote de dados).

A multitela surge não como um consumo duplicado (assistir algo no celular e na TV ao mesmo tempo), mas como um recurso para poder ver o que deseja quando a tela preferida (que pode ser a TV ou o computador, por conta da qualidade ou do conforto físico) já está sendo utilizada por outro morador da casa ou não pode ser mais usada:

É, acho que todo mundo prefere ver mais [série] pelo celular, principalmente porque os meus pais não curtem muito as séries que eu gosto. (São Paulo)

A bateria não segura mais a carga, descarrega muito rápido. Mas se eu assistir um episódio ele vai descarregar todinho, aí, eu estou agora pelo notebook. (Vitória de Santo Antão)

A tendência dos ouvidos é sempre maximizar o consumo de conteúdos gratuitos (nem sempre legalizados), mas a decisão de compra de certos produtos aparece nas discussões das três classes, nas três cidades. Eles refletem sobre a relação entre custo e benefício antes de decidir pelo gasto: regem a compra, o apreço pelo artista ou serviço, ou ainda o tempo de diversão (comparado ao preço cobrado) proporcionado pelo produto:

[sobre vídeo on demand na TV a cabo] Nunca aluguei, porque qual é o sentido de pagar $R \$ 12$ para alugar um filme, sendo que...

Netflix é $R \$ 30$ por mês. Você tem um acervo todinho e filmes. (Vitória de Santo Antão)

Eu pago [Spotify], eu gosto, eu estou na rua quero ouvir alguma música, só pesquisar, procuro e acho a música que eu quiser. (São Paulo)

Moderadora: Você já foram à Lan House assistir a vídeos?

Já

Assistir a um filme de duas horas vai ter que... Você tem dinheiro?

[...]

Às vezes não tem Internet, a Internet está ruim, vai na Lan House. (Cachoeira do Sul)

Em relação à diversidade, a religião surge como variável relevante para a compreensão do processo de consumo de jovens de diferentes regiões e status socioeconômicos, principalmente nas práticas culturais ligadas à música. Nota-se que esse consumo se configura como um traço de identidade, que os rapazes e moças fazem questão de ressaltar nas discussões em que participam:

Tem uma banda que eu gosto muito daqui, é uma banda de louvor, canção de louvor. Eles são muito conhecidos aqui e estão muito conhecidos no Brasil inteiro, viajam muito, vão para São Paulo, todos os lugares do Brasil, estava olhando hoje os vídeos deles. Tem muitos, milhões de visualizações. (Vitória de Santo Antão)

É, digital eu gosto de ler.

Moderadora: Tipo o quê? Qual o assunto?

Na verdade eu leio, sei lá o que abre, o que chama a atenção, por exemplo, essas coisas saem bastante em jornal a gente lê. Por exemplo, a Bíblia eu leio.

Moderadora: O que tu busca na Internet?

Filmes, tem músicas também. Bastante pregações. (Cachoeira do Sul) 
Sobre a valorização das culturas nacionais e regionais, percebemos que a indústria cultural de países desenvolvidos é avaliada como superior (gera produtos mais interessantes, mas sofisticados) pelos jovens de menor renda (em São Paulo), enquanto os do Nordeste demonstram preocupação com o domínio da cultura estrangeira, que pode gerar subvaloração da cultura popular nordestina. Em Cachoeira do Sul, não houve esse debate específico, mas artistas locais não foram citados. Nesse caso, ainda que o Rio de Grande do Sul e Pernambuco partilhem de fortes tradições culturais regionais, o apreço por práticas locais aparece apenas no grupo de Vitória de Santo Antão, o que denota o papel que tem o estatuto socioeconômico (e com ele a melhor formação educacional, claramente notada nas discussões) na reflexão sobre a cultura endógena, nesse caso. Chama-nos atenção o fato de que os jovens de classes sociais mais altas entendem cultura a partir do conceito de "reflexão", enquanto os de menor rendimento, em São Paulo ou no Rio de Grande do Sul, a associam a "aprendizado", como se, por meio da cultura, tivessem necessariamente de conhecer algo novo, e não reproduzir e expandir aquilo que já conhecem, que lhes é próprio. Eis um importante indicador para o investimento nessas questões nos currículos educacionais, sobretudo nas escolas públicas, que são frequentadas pelos jovens de menor rendimento.

Moderadora: Você gosta de ler?

Muito, porém eu não gosto de livro brasileiro, nunca li nenhum.

[...] tudo o que a gente vê aqui para nós é ultrapassado, porque a gente está muito próximo deles [Europa, EUA], a gente vê tudo deles, tudo deles é melhor, o transporte, de uma formiga que nasce até Deus, tudo é melhor, tudo é melhor. Lá é um país desenvolvido. Aqui é subdesenvolvido.

Tudo deles é exemplo pra gente. (São Paulo)

A gente está inserido nesse contexto que a gente está como jovem de 17 anos, se a gente deixar de acessar essa cultura que busca assistir séries, ler livros on-line, eu uso praticamente todas as redes sociais, a gente não vai mais estar inserido... A gente vai estar ali só que é como se não estivesse.

Moderadora: Fica deslocado, não é?

Como se a gente absorvesse a cultura de outros lugares

[...]

De outros lugares e esquecendo da nossa. (Vitória de Santo Antão)

Ainda sobre a cultura local, os artistas regionais passam a ser conhecidos sobretudo pela rede de contatos dos garotos e garotas, e menos por divulgação em páginas da Internet. Essa troca de informações pessoais envolve banners e outros materiais divulgados pelos produtores culturais, mas o contato com essas propagandas só ocorre porque uma pessoa o fez circular em grupos de mensagens instantâneas (o WhatsApp, no caso) ou de redes sociais (o Facebook). Essa observação revela que a mesma lógica rege o consumo cultural nas periferias de São Paulo ou no interior sulista ou nordestino. Não se sabe, no entanto, pelos grupos analisados aqui, se estrutura similar apareceria em relatos de jovens das zonas centrais de ricas capitais brasileiras (o que deve ser aprofundado em novas pesquisas).

Esse fato deve ser analisado em conjunto com o apontamento de que os jovens buscam, em sites como YouTube, em playlists do Spotify ou iTunes, ou em redes sociais, artistas que já conhecem ou admiram. O "novo" é, por vezes, descoberto em listas indicadas por essas plataformas. Não há, nos grupos ouvidos, discussões aprofundadas sobre essas sugestões: elas costumam ser consideradas boas, pois resolvem problemas como "preguiça" de buscar algo nas plataformas ou "indecisão" do que ouvir em seguida. Aponta-se aqui, portanto, as limitações da circulação de produções independentes ou fora do circuito comercial nos grandes conglomerados on-line, que concentram a audiência. 
Os grupos também indicaram que as ofertas na Internet ampliam suas práticas culturais, já que o consumo físico tem obstáculos como custo de compra, transporte, alimentação e ingressos ou falta de ofertas interessantes próximas (seja nas pequenas cidades, seja nas periferias): não apenas espetáculos de músicos de grande fama nacional ou internacional mas também museus, bibliotecas, exposições e cinemas. No entanto, é consenso entre os jovens ouvidos que a opção on-line não substitui a vivência in loco, tida como mais completa, por conta do envolvimento de todos os sentidos na fruição artística, e também como forma de interação social. Trata-se de um braço que expande e muitas vezes estimula a vivência física, mas que é, em algum modo, menor do que ela.

Quando você lê pela Internet parece que você lê mais rápido.

Não é a mesma emoção. Aquele negócio que você está lendo e aconteceu uma coisa que você nunca esperou, você fecha o livro e fica: meu Deus, o que eu acabei de ler? (Vitória de Santo Antão)

[Moderadora] Vocês acham que essas atividades que vocês gostariam que tivesse aqui, o acesso a essas atividades poderia ser por Internet, ou não? Assistir a um show pela Internet?

Na minha opinião tem como fazer isso. Hoje já tem como fazer. Aqui em Cachoeira nem tem show poucas vezes aberto. Mas acho que não seria tão legal como se tu tivesse lá.

É igual você ver a torre Eiffel pelo Google. Você nunca vai... ou o Cristo, ou qualquer coisa assim.

A sensação.

Acho que tudo pelo celular perde a essência. (São Paulo)

Ao mesmo tempo, produções exclusivamente on-line, como canais de vloggers, são em geral consideradas engraçadas, porém fúteis, e não aparecem indicações de produções próprias de conteúdo cultural (para além de pequenos vídeos ou textos para redes sociais, não consideradas por eles como formas de expressão cultural nem como algo de interesse amplo), com a exceção de um blog com receitas, realizado por um garoto de São Paulo. Daí, conclui-se que, novamente, há a necessidade de investimento em Literacia digital para que os jovens possam ser estimulados a usar canais e ferramentas on-line para realizar produções culturais próprias, e que sejam mais interessantes e instigantes do que as que eles observam existir atualmente.

A título de conclusão, afirmamos a necessidade de investimento na inclusão digital da população brasileira (seja em infraestrutura, seja em condições mais acessíveis para a aquisição do serviço) e em políticas públicas culturais (e educacionais) que possam despertar a atenção para a importância da diversidade cultural e da valorização das tradições nacionais e locais (sem a perda das trocas culturais entre nações), além de estimular a produção cultural pessoal como forma de expressão, de construção e afirmação de identidades e, também, desenvolvimento local e nacional.

\section{Referências}

BRASIL. Instituto Brasileiro de Geográfica e Estatística. Sistema de informações e indicadores culturais. Rio de Janeiro, 2013.

Ministério da Cultura. Cultura em números: anuário de estatísticas culturais. Brasília, DF, 2010a. 
Ministério da Cultura. Plano Nacional de Cultura. Brasília, DF, 2010b. Disponível em: <http://bit.ly/2j1Clbu>. Acesso em: 16 jan. 2017.

. Ministério da Cultura. Plano Nacional de Cultura: entenda o plano. 2010c. Disponível em: <http://bit.ly/2iEl8el>. Acesso em: 16 jan. 2017.

CÁDIMA, F. R. A Google, o sistema de media e a agregação de informação. Intercom - Revista Brasileira de Ciências da Comunicação, São Paulo, v. 35, n. 1, p. 19-37, 2013.

CETIC.BR. FAQ - TIC Cultura. São Paulo: Cetic.br, [s.d.]. Disponível em: <http://bit.ly/2iztGBs>. Acesso em: 16 jan. 2017.

EAGLETON, T. A ideia de cultura. 1. ed. São Paulo: Unesp, 2005.

HANSEN, A. et al. Mass communication research methods. New York: New York University, 1998.

INTERNATIONAL TELECOMMUNICATION UNION. Manual for Measuring ICT Access and Use by Households and Individuals. Geneva: International Telecommunication Union, 2014.

ORGANIZAÇÃO DAS NAÇÕES UNIDAS PARA A EDUCAÇÃO, A CIÊNCIA E A CULTURA. Convenção sobre a proteção da diversidade das expressões culturais. [s.I.]: Unesco, 2005. Disponível em: <http://bit.ly/2jswpAG>. Acesso em: 16 jan. 2017.

SANTAELLA, L. Culturas e artes do pós-humano: da cultura das mídias à cibercultura. São Paulo: Paulus, 2003.

SCHMITZ, D. et al. Jovem brasileiro e consumo midiático em tempos de convergência: panorama preliminar. In: CONGRESSO LATINOAMERICANO DE INVESTIGADORES DE LA COMUNICACIÓN, 12., 2014, Lima. Anais... Lima: Alaic, 2014.

SERVIÇO SOCIAL DO COMÉRCIO. Públicos de cultura. Rio de Janeiro: Sesc, 2013. Disponível em: <http://bit.ly/1tEKdp7>. Acesso em: 16 jan. 2017.

SUNKEL, G. El acceso de los jóvenes a la cultura en la era digital en América Latina. In: TRUCCO, D.; ULLMANN, H. (Ed.). Juventud: realidades y retos para un desarrollo con igualdad. Santiago: Comisión Económica para América Latina y el Caribe, 2015. p. 171-206

UNESCO INSTITUTE FOR STATISTICS. The 2009 Unesco framework for cultural statistics. 2009. Montreal: Unesco, 2009. Disponível em: <http://bit.ly/1WPKRhe>. Acesso em: 15 jul. 2016.

VIEIRA, M. P. Reinventando sentidos para a cultura: uma leitura do papel normativo da Unesco através da análise da convenção sobre a proteção e promoção da diversidade das expressões culturais. 2009. 303 F. Tese (Doutorado em Ciências Sociais) - Universidade Federal da Bahia, Salvador, 2009.

WILLIAMS, R. Cultura. São Paulo: Paz e Terra, 2000. 